Journal Of Nursing Practice

http://jurnal.strada.ac.id/jnp

Vol.1 No.1 Oktober 2017. hlm 1 - 8

\title{
Pengaruh Lingkungan Keluarga Terhadap Perkembangan Psikososial Pada Anak Prasekolah
}

\author{
Heri Saputro ${ }^{1}$, Yufentri Otnial Talan ${ }^{2}$ \\ ${ }^{1,2}$ STIKes Surya Mitra Husada Kediri \\ intelsehat@gmail.com
}

\begin{abstract}
The number of disorders in children such as lack of socialization, lack of initiative and a lot of silence for fear of doing an act indicates a psychosocial problem in children, and one of the factors that can affect the development of psychosocial disorders of children is the family environment. The purpose of this study to determine the influence between the family environment on psychosocial development in children aged 4-6 years in Tosaren Village.The study design was observational with cross sectional approach. Respondents were taken using simple random sampling technique. Population in this study All children aged 4-6 years in Tosaren Village as many as 147 respondents, a sample of 108 respondents. The independent variable is the family environment, the dependent variable of psycho-child development. Results of analysis using logistic regression statistical testas $\alpha=0.05$. The results showed that almost all children aged 4-6 in Tosaren sub-district with authoritarian family environment were $90(83,3 \%)$ respondents, mostly children aged 4-6 in Tosaren with guilt psychocic development that was $75(69,4 \%)$ Of respondents from a total of 108 respondents. The results of data analysis showed that the level of significance value of $p$ - value $=0,000$ so the H1 accepted which means there is influence of family environment on the psychosocial development of children aged 4-6 years in the Village Tosaren.A good family environment is a very supportive situation in optimizing the personal social development of pre school children. Therefore, parents as those who are closest to the child should be able to be role models, show good examples and can guide and provide direction to children in a good way without having to force children to follow all the rules of parents.
\end{abstract}

Keywords: Family Environment, Psychosocial Development, Pre-school Children

Received August 15, 2017; Revised September 07, 2017; Accepted October 01, 2017

How to Cite: Saputro, H \& Talan, Y.O. (2017). Pengaruh Lingkungan Keluarga Terhadap Perkembangan Psikososial Pada Anak Prasekolah. Journal Of Nursing Practice. 1(1). 1-8. 
Journal Of Nursing Practice

http://jurnal.strada.ac.id/jnp

Vol.1 No.1 Oktober 2017. hlm 1 - 8

\section{PENDAHULUAN}

Banyaknya gangguan pada anak seperti kurang bersosialisasi, kurang inisiatif dan banyak diam karena takut salah dalam melakukan sebuah tindakan menandakan adanya masalah psikososil pada anak, apabila gangguan tersebut berlangsung secara menerus akan berdampak kurang baik bagi perkembangan kepribadian anak, yang berbahaya pada tahap ini adalah tidak tersalurkannya energi yang mendorong anak untuk aktif (dalam rangka memenuhi keinginannya), karena mengalami hambatan atau

kegagalan sehingga dapat memperberat rasa bersalah pada anak. Rasa bersalah inilah yang akan berdampak kurang baik bagi perkembangan kepribadian anak, dia bisa menjadi nakal atau pendiam (kurang bergairah), salah satu faktor yang dapat mempengaruhi terjadinya gangguan perkembangan psikososial anak yaitu lingkungan keluarga.

Lingkungan keluarga merupakan aspek yang pertama dan utama dalam mempengaruhi perkembangan anak. Anak lebih banyak menghabiskan waktunya di lingkungan keluarga, sehingga keluarga mempunyai peran yang banyak dalam membentuk perilaku dan kepribadian anak serta memberi contoh nyata kepada anak. Karena di dalam keluarga, anggota keluarga bertindak seadanya tanpa dibuat-buat. Dari keluarga inilah baik dan buruknya perilaku dan kepribadian anak terbentuk. Walaupun ada juga faktor lain yang mempengaruhi. Orang tua merupakan contoh yang paling mendasar dalamkeluarga. Apabila orang tua berperilaku kasar dalam keluarga, maka anak cenderung akan meniru. Begitu juga sebaliknya, orang tua yang berperilaku baik dalam keluarga, maka anak juga cenderung akan berperilaku baik.

Menurut Biro Pusat Statistik (BPS) Provinsi Jawa Timur tahun 2015 penduduk jawa Timur berjumlah 38.052.950 jiwa, dengan jumlah anak Pra sekolah sebanyak 2.196.856. Data yang diperoleh dari Dinas Kesehatan Kota Kediri Menyebutkan bahwa di kota kediri mempunyai jumlah balita dan anak prasekolah sebanyak 24.523,yang dilakukan deteksi dini hanya 7.622 balita dan anak prasekolah. Hal ini menunjukan bahwa belum dilakukan deteksi dengan tepat sehingga tidak bisa diketahui jumlah anak yang sesungguhnya.

Kelurahan Tosaren Kota kediri terdiri dari 16 RW dan 46 RT. Berdasarkan studi pendahuluan yang dilakukan di Kelurahan Tosaren pada tanggal 6 Ferbruari, 2017 didapatkan jumlah anak usia 4-6 tahun pada tahun 2015 tercatat ada 117 anak. Sedangkan pada tahun 2016 jumlah anak usia 4-6 tahun dikelurahan Tosaren tercatat ada 148 anak. Hasil wawancara dengan dengan 8 orang tua yang memiliki anak usia 4-6 tahun, 5 orang tua mengatakan tidak memberikan kesempatan kepada anak untuk melakukan apa yang anak inginkan dan semua keputusan yang dibuat berdasarkan kemauan orang tua, dan semua itu harus diikuti oleh anak. Tiga orang tua mengatakan memberikan kebebasan kepada anak untuk menetukan pilihannya tetapi harus sesuai dengan norma dan aturan yang berlaku dalam keluarga dan masyarakat.

Sebagai calon generasi penerus bangsa, kualitas tumbuh kembang anak perlu mendapat perhatian serius, 


\section{Journal Of Nursing Practice}

http://jurnal.strada.ac.id/jnp

Vol.1 No.1 Oktober 2017. hlm 1 - 8

karena perkembanga individu terjadi secara simultan antara dimensi fisik, kognitif, psikososial, moral dan spiritual. Pencapaian tugas perkembangan psikososial agar tidak terjadi hambatan yang serius pada anak prasekolah, perlu diperhatikan faktor psikososial ysng dapat mempengaruhi tumbuh kembang anak antara lain; stimulus, motifasi belajar, ganjaran atau hukuman, kelompok sebaya, stress, sekolah, cinta dan kasih sayang serta pola asuh orang tua.

Anak prasekolah biasanya akan meniru apa yang di ajarkan oleh orang tua, baik secara langsung maupun tidak langsung. Sehingga orangtua harus mampu meningkatkan pengetahuan dan kemampuan dalam menciptakan lingkungan dan kondisi keluarga yang kondusif guna menunjang proses perkembangan anak. Tujuan Penelitian ini adalah untuk mengetahui pengaruh antara

lingkuangan keluarga terhadap perkembangan psikososial pada anak usia 4-6 tahun di Kelurahan Tosaren

\section{METODE PENELITIAN}

Desain penelitian adalah observasional dengan pendekatan cross sectional. Responden diambil dengan menggunakan teknik Simple random Sampling. Populasi dalam penelitian ini Semua anak usia 4-6 tahun di Kelurahan Tosaren sebanyak 147 responden, sampel sebanyak 108 responden. Variabel independen adalah lingkungan keluarga, variabel dependen perkembangan psikosoial anak. Hasil analisis dengan menggunakan uji statistik Regresi logistic $\alpha=0,05$.

\section{HASIL PENELITIAN Karakteristik Subyek}

Tabel 1. Karakteristik responden dalam penelitian ini meliputi usia orang tua, pendidikan, pekerjaan, usia anak, jenis kelamin anak, lingkungan keluarga dan perkembagan psikologi anak.

\begin{tabular}{|c|c|c|c|c|}
\hline \multirow{2}{*}{$\begin{array}{r}\text { No } \\
1\end{array}$} & Karakteristik & \multicolumn{2}{|r|}{$\mathbf{\Sigma N}$} & \multirow[t]{2}{*}{$\Sigma \%$} \\
\hline & \multicolumn{2}{|c|}{ Usia orang tua (th) } & \multirow[b]{2}{*}{18} & \\
\hline & $<25$ & & & 17 \\
\hline & $25-30$ & & 59 & 55 \\
\hline & $31-35$ & & 27 & 25 \\
\hline & $>35$ & & 3 & 3 \\
\hline \multirow[t]{4}{*}{2} & Pendidikan & & & \\
\hline & SMP & \multicolumn{2}{|r|}{44} & 41 \\
\hline & SMA & \multicolumn{2}{|r|}{52} & 48 \\
\hline & PT & \multicolumn{2}{|r|}{12} & 11 \\
\hline \multirow[t]{5}{*}{3} & Pekerjaan & \multirow{2}{*}{\multicolumn{2}{|c|}{22}} & \\
\hline & IRT & & & 20 \\
\hline & Swasta & \multicolumn{2}{|r|}{38} & 35 \\
\hline & Wiraswasta & \multicolumn{2}{|r|}{40} & 37 \\
\hline & PNS & \multicolumn{2}{|r|}{9} & 8 \\
\hline 4 & \multicolumn{4}{|l|}{ Usia Anak (th) } \\
\hline 4 & & \multicolumn{2}{|l|}{39} & 36 \\
\hline 5 & & \multicolumn{2}{|l|}{54} & 50 \\
\hline 6 & & \multicolumn{2}{|l|}{15} & 14 \\
\hline \multicolumn{5}{|c|}{$5 \quad$ Jenis kelamin anak } \\
\hline \multicolumn{2}{|c|}{ Laki-laki } & 74 & \multicolumn{2}{|c|}{69} \\
\hline & & 34 & \multicolumn{2}{|c|}{31} \\
\hline \multicolumn{5}{|c|}{6 Lingkungan keluarga } \\
\hline \multicolumn{2}{|c|}{ Otoriter } & 90 & \multicolumn{2}{|c|}{83,3} \\
\hline \multicolumn{2}{|c|}{ Demokratis } & 18 & \multicolumn{2}{|c|}{16,7} \\
\hline
\end{tabular}


Journal Of Nursing Practice

http://jurnal.strada.ac.id/jnp

Vol.1 No.1 Oktober 2017. hlm 1 - 8

\begin{tabular}{lll}
\hline Bersalah & 75 & 69,4 \\
Inisiatif & 33 & 30,6 \\
\hline Total & $\mathbf{1 0 8}$ & $\mathbf{1 0 0}$ \\
\hline
\end{tabular}

Sumber: Hasil analisa data, Tahun 2017

Berdasarkan tabel 1 diatas dari total 108 responden sebagian besar respondenberusia 20-35 tahun yaitu sebanyak 59 responden (55\%), berpendidikan SMA yaitu sebanyak 59 responden (48\%), bekerja di bidang wiraswasta/berdagang yaitu sebanyak 59 responden (48\%), usia anak responden yaitu 5 tahunsebanyak 54 responden (50\%), berjenis kelamin laki-laki yaitu sebanyak 74 responden (69\%), hampir seluruh anak usia 4-6 di kelurahan Tosaren dengan lingkungan keluarga otoriter yaitu sebanyak 90 responden $(83,3 \%)$ dan perkembangan psikosial bersalah yaitu sebanyak 75 responden $(69,4 \%)$.

Tabel 2.Pengaruh lingkungan keluarga terhadap perkembangan psikososial pada anak usia 4 - 6 tahun di Kelurahan Tosaren (Tanggal 20-29 Juli 2017)

\begin{tabular}{lc}
\hline Variabel & Nilai Signifikan \\
\hline Pengaruh lingkungan & \\
keluarga terhadap & \\
perkembangan & \\
psikososial pada & 0.000 \\
anak usia $4-6$ tahun & \\
di Kelurahan & \\
Tosaren. & \\
\hline
\end{tabular}

Berdasarkan hasil uji statistik regresi logistikyang telah dilakukan diketahui bahwa nilai pvalue $=0,000<\alpha 0,05$ sehingga $\mathrm{H} 1$ diterima yang artinya terdapat pengaruh

lingkungan keluarga terhadap perkembangan psikososial pada anak usia 4 - 6 tahun di Kelurahan Tosaren.

\section{PEMBAHASAN}

\section{Lingkungan keluarga anak usia 4-6 di Kelurahan Tosaren Kota Kediri.}

Hasil penelitian menunjukan bahwa 90 (83.3\%) responden dengan lingkungan keluarga otoriter, 18 (16.7\%) responden dengan lingkungan keluarga demokratis dari total 108 responden di kelurahan Tosaren Kota Kediri. Lingkungan keluarga yaitu lingkungan yang bertanggung jawab atas kelakuan, pembentukkan kepribadian, kasih sayang, perhatian, bimbingan, kesehatan dan suasana rumah. Dari lingkungan keluarga yang baik yang mampu memancarkan keteladanan kepada anak-anaknya, akan lahir anak-anak yang memliki kepribadian dengan pola yang mantap. Menurut Hurlock (2007), jenis lingkungan keluarga ada 3 yaitu otoriter, Otoriter merupakan jenis lingkungan keluarga yang mengekang dan tidak memberi kebebasan sama sekali, semua peraturan dari orang tua harus ditaati, tidak memperhatikan kemauan dan kemampuam yamg dimiliki oleh anak, sehingga anak kurang bisa mengembangkan potensi yang dimiliki, 2) Demokratis, Demokratis merupakan jenis lingkungan keluarga yang memberi kebebasan kepada anak untuk mengembangkan potensi yang dimiliki, tanpa mengabaikan peraturan dan norma- 
norma yang harus ditaati, 3) Bebas, Bebas merupakan jenis lingkungan keluarga dimana orang tua tidak memberikan aturan dan norma-norma yang harus ditaati oleh anak, sehingga anak merasa bebas, dan kebanyakan mereka terjebak dalam hal-hal yang negatif karena kurangnya perhatian orang tua. Perilaku pola asuh dalm lingkungan keluarga yang diterapkan pada anaknya dipengaruhi oleh faktor tingkat pendidikan, lingkungan, dan social budaya.

Hasil penelitian menunjukan hampir seluruh keluarga menerapakan lingkungan keluarga otoriter. Hal ini menunjukan bahwa keluarga dengan sikap yang otoriter di kelurahan Tosaren Tosaren sangat tinggi karena angkanya mencapai $83,3 \%$. Sikap otoriter yang diterapakan orang tua kepada anak usia 4-6 tahun di Kelurahan Tosaren disebabkan karena masih kurangnya pemahaman orang tua tentang bagaimana cara memperlakukan anak pada jaman sekarang ini, mereka masih menganut kebiasaan lama yang diterapkan oleh orang tua mereka dulunya, serta masih kurangnya pemahaman orang tua akan dampak dari sikap otoriter mereka terhadap anak, dimana anak harus selalu mengikuti segala sesuatu yang telah ditetapkan orang tua. Berdasarkan hasil wawancara dengan dengan pada orang tua dengan sikap otoriter, mereka mengatakan bahwa semua aturan yang telah dibuat harus diikuti oleh anak, orang tua juga mengatakan bahwa alansan mereka memperlakukan anak dengan sikap otoriter supaya membiasakan anak mengikuti aturan yang telah dibuat dan tidak membengkang setelah sudah besar nanti, dan ini juga merupakan kebaikan untuk anak. Pada hasil penelitian juga menunjukan bahwa sebagian kecil keluarga menerapkan sikap demokratis pada anak, hal ini terjadi karena orang tua telah mengetahui dan memahami akan manfaat dari sikap yang demokratis, dimana orang tua tidak selalu memaksakan kehendak dan sesekali mendengarkan permintaan anak apabila permintaan anak tersebuat baik dan bermanfaat.

\section{Perkembangan psikososial pada anak usia 4-6 tahun di Kelurahan Tosaren Kota Kediri.}

Hasil penelitian menunjukan bahwa 75 anak (69.4\%) dengan perkembangan psikososial bersalah dan 33 anak (30.6\%) dengan perkembangan psikososial inisiatif dari total 108 responden di kelurahan Tosaren Kota Kediri. Perkembangan untuk mencapai manusia dewasa, seorang anak sejak lahir akan melalui berbagai tahap perkembangan, salah satunya adalah masa prasekolah yaitu antara usia 4-6 tahun dengan perkembangan psikososialnya. Pada masa prasekolah usia 4-6 tahun merupakan masa dimana anak mulai mengeksplorasi tingkah lakunya dan keinginan-keingannya serta anak mulai aktif melakukan aktivitasnya, dan apabila anak usia 4-6 tahun gagal melalui tahap ini akan berdampak pada perkembangan anak. Tahap prasekolah menurut Erikson merupakan tahap dimana anak memasuki fase inisiatif vs kesalahan, pada tahap ini tugas yang harus diemban seorang anak adalah untuk belajar punya gagasan (inisiatif) tanpa banyak terlalu melakukan banyak kesalahan. Tekanan yang berlebihan ataupun pengharapan yang terlalu tinggi melampaui kapasitas membuat anak untuk berbohong atau berbuat curang agar dapat diterima dikelompok sosialnya.

Faktor-faktor yang mempengaruhi perkembangan sosial personal anak prasekolah antara lain faktor keluarga dan kematangan anak. Kondisi dan tata cara kehidupan keluarga merupakan lingkungan yang kondusif bagi sosialisasi anak. Masalah sosial emosional sering terjadi pada anak, sekitar 9,5-14,2\% anak mengalami gangguan sosial emosional yang nantinya akan berdampak negatif pada pertumbuhan, perkembangan dan kesiapannya untuk bersekolah. Hasil penelitian 
menunjukan bahwa sebagian besar anak usia 4-6 di Kelurahan Tosaren dengan perkembangan psikososial bersalah, hal ini akan berdampak pada perkembangan anak menuju soerang remaja dan dewasa.

Pada anak dengan psikososial bersalah akan menyababkan kurangnya kemampuan anak dalam melakukan eksplorasi dirinya, karena anak takut berbuat salah dalam melakukan sesuatu, sehingga anak lebih banyak pasif. Adapun faktor yang mempengaruhi tingginya masalah psikososial pada anak di Kelurahan Tosaren karena orang tua selalu melarang dan memarahi anak ketika melakukan sesuatu.

Dari fakta dan teori di atas dapat dilihat bahwa faktor yang paling utama dalam mempengaruhi perkembangan sosial personal anak adalah keluarga. Ketika orang tua memberikan kebebasan kepada anak untuk banyak bergaul dengan teman sebayanya maka mereka akan lebih terbuka untuk menerima dunia luar, lebih mandiri, dan mempunyai perkembangan sosial yang lebih baik. sebaliknya jika orang tua selalu melarang anak dalam melakukan dan mengikuti suatu kegiatan maka akan menyebabkan anak selalu tergantung dengan keptusan orang tua dan akan berpengaruh pada perkembangan psikososal anak kearah yang negatif yaitu makin meningkatnya rasa bersalah yang dialami oleh anak.

\section{Pengaruh lingkungan keluarga terhadap perkembangan psikososial pada anak usia 4 - 6 tahun di Kelurahan Tosaren Kota Kediri}

Berdasarkan hasil uji statistik regresi ordinal yang telah dilakukan diketahui bahwa nilai $p$ value $=0,000$ sehingga $\mathrm{H} 1$ diterima yang artinya terdapat pengaruh lingkungan keluarga terhadap perkembangan psikososial pada anak usia $4-6$ tahun di Kelurahan Tosaren. Sedangkan tabulasi silang antara lingkungan keluarga dengan perkembangan psikososial anak menunjukan bahwa sebagian besar anak di kelurahan Tosaren dengan lingkungan keluarga otoriter memiliki perkembangan psikososial bersalah yaitu sebanyak 75 responden $(69,4 \%)$ dari total 108 responden.

Perkembangan psikososial merupakan perkembangan yang membahas tentang perkembangan kepribadian manusia, khususnya yang berkaitan dengan emosi, motifasi dan perkembangan kepribadian. Sikap lingkungan yang suka melarang dan menyalahkan membuat anak kehilangan inisiatif. Pada saat dewasa anak akan mudah mengalami rasa bersalah bila melakukan kesalahan dan tidak kreatif. Sebagai calon generasi penerus bangsa, kualitas tumbuh kembang anak perlu mendapat perhatian serius, karena perkembanga individu terjadi secara simultan antara dimensi fisik, kognitif, psikososial, moral dan spiritual. Masing-masing dimensi mempunyai peran yang sama pentingnya untuk membentuk kepribadian yang utuh. Pencapaian tugas perkembangan psikososial agar tidak terjadi hambatan yang serius pada anak prasekolah, perlu diperhatikan faktor psikososial yang dapat mempengaruhi tumbuh kembang anak antara lain; stimulus, motifasi belajar, ganjaran atau hukuman, kelompok sebaya, stress, sekolah, cinta dan kasih sayang serta pola asuh orang tua.

Anggota keluarga merupakan lingkungan pertama anak dan orang yang paling penting selama tahun-tahun formatif awal. Hubungan dengan anggota keluarga menjadi landasan sikap terhadap orang, benda, dan kehidupan secara umum. Mereka juga meletakan landasan bagi pola penyesuaian dan belajar berpikir tentang diri mereka sebagai mana dilakukan anggota keluarga mereka. Tingkat pendidikan yang dimiliki oleh orangtua yaitu sederajat sangat berpengaruh terhadap kepribadian. Kepribadian baik yang dimiliki oleh orangtua memiliki pengaruh positif 
terhadap lingkungan sekitar, karena orangtua sebagai panutan di dalam keluarga, termasuk anak. Anak prasekolah biasanya akan meniru apa yang di ajarkan oleh orang tua, baik secara langsung maupun tidak langsung. Sehingga orangtua harus mampu meningkatkan pengetahuan dan kemampuan dalam menciptakan lingkungan dan kondisi keluarga yang kondusif guna menunjang proses perkembangan anak. Pola kepribadian merupakan suatu penyatuan struktur yang multidimensi. Konsistensi, artinya sifat diharapkan dapat menjadi perilaku. Perkembangan sifat dipengaruhi oleh dua faktor, yaitu hereditas (bawaan) dan belajar, bentuk belajar antara lain, karena pengasuhan orangtua dan imitasi (peniruan) anak terhadap idolanya.

Berdasarkan hasil penelitian dan teori yang telah dijabarkan diatas peneliti berpendapat bahwa lingkungan keluarga memiliki pengaruh yang besar terhadap perkembangan psikososial anak. Dimana semakin baik lingkungan keluarga dalam hal ini lingkungan keluarga yang demokratis maka akan semakin baik perkembangan psikososial anak menuju kearah yang lebih kreatif, karena anak memiliki kebebasan dalam mengeplorasikan dirinya tanpa adanya aturan-aturan yang terlalu membatasi anak dalam melakukan kegiatan yang diinginkan oleh anak. Begitupun sebaliknya pada lingkungan keluarga yang kurang baik akan menyababkan perkembangan psikososoal anak terganggu dimana anak akan menjadi soerang pemalu, pendiam, bahkan menjadi hiperaktif. Lingkungan keluarga yang baik merupakan suatu keadaan yang sangat mendukung dalam mengoptimalkan perkembangan sosial personal anak usia pra sekolah. Oleh sebab itu, orang tua sebagai orang yang paling dekat dengan anak harus dapat menjadi panutan, menunjukan contoh-contoh yang baik serta dapat membimbing dan memberikan arahan kepada anak dengan cara yang baik dan benar tanpa harus memaksakan anak untuk mengikuti semua aturan orang tua, sehingga perkembangan psikososial anak berjalan dengan baik tanpa adanya masalah yang akan berpengaruh pada pertumbuhan dan perkembangan anak selanjutnya.

\section{KESIMPULAN DAN SARAN}

1. Hampir seluruh anak usia 4-6 di

kelurahan Tosaren dengan lingkungan keluarga otoriter yaitu sebanyak 90 responden $(83,3 \%)$ dari total 108 responden.

2. Sebagian besar anak usia 4-6 di kelurahan Tosaren dengan perkembangan psikosial bersalah yaitu sebanyak 75 responden $(69,4 \%)$.

3. Ada pengaruh lingkungan keluarga terhadap perkembangan psikososial pada anak usia $4-6$ tahun di Kelurahan Tosaren, dengan nilai $p$ value $=0,000$.

\section{DAFTAR PUSTAKA}

BKKBN. (2009). Pengasuhan dan Pembinaan Tumbuh Kembang Anak. Jakarta.

Hidayat T (2010). Agar Anak Tak Pendek Akal. Jakarta: Salemba Medika.

Hurlock B.E，2007. Psikologi Perkembangan Suatu Pendekatan Sepanjang Rentang Kehidupan. Penerbit Erlangga. Jakarta. 
Journal Of Nursing Practice

http://jurnal.strada.ac.id/jnp

Vol.1 No.1 Oktober 2017. hlm 1 - 8

Keliat. (2011). Pola Asuh Orang Tua Dan Komunikasi Dalam Keluarga. Jakarta : Rineka Cipta.

Nelson. (2012). Ilmu kesehatan anak. Jakarta: EGC.

Petantro I. (2011). Rasa percaya diri anak adalah pantulan pola asuh orang tua. http://www.dampakpolaasuh.co.uk/ [Diakses tanggal 4 februari 2017]

Ramli.2011. Perkembangan Anak Jilid 2Edisi Keenam.Alih bahasa oleh Meitasari Tjandarasa. Jakarta: Erlangga.

Setyowati Sri. S.Kep dkk.(2008).Asuhan Keperawatan Keluarga, konsep dan apilkasi kasus; editor HandokoRiwidikdo, Skp dkk- Jogjakarta : Mitra cendikia

Soekanto, Soerjono. 2007. Sosiologi suatu Pengantar. Jakarta: P.T.Raja Grafindo. Soetjiningsih. (2010). Tumbuh kembang anak. Jakarta: EGC.

Shocib. (2010). Pola asuh orang tua. Jakarta: Rineka Cipta.

Supartini (2011). Buku ajar konsep dasar keperawatan anak. Jakarta. EGC

Santrock, John W. (2013). Masa Perkembangan Anak. Jakarta: Salemba Medika. 